\title{
CORRIGENDUM
}

\section{Possible density dependent local variations in the IMF - CORRIGENDUM}

\section{Indulekha Kavila and Babitha George}

doi:10.1017/S1743921316008012, Published by Cambridge University Press $12^{\text {th }}$ September 2016 .

In the article by Kavila \& George (2016) published in Proceedings IAU Symposium No. 315 there was an error with the author's affiliations. The correct affiliation is:

School of Pure \& Applied Physics, Mahatma Gandhi University, KERALA 686560 INDIA

email: indulekha@mgu.ac.in, kindulekha@gmail.com

\section{Reference}

Kavila, I., \& George, B. 2016, IAU Symp. No. 315, E40 1-2 